\title{
AS NOVAS MÍDIAS E O ATIVISMO DIGITAL NA PROTEÇÃO DO MEIO AMBIENTE: ANÁLISE DO SITE GREENPEACE.ORG
}

\author{
Noemi de Freitas Santos ${ }^{1}$ \\ Carine Belinazzo ${ }^{2}$ \\ Janice Cristiani Bên Macedo ${ }^{3}$
}

\begin{abstract}
RESUMO: Os movimentos sociais passam por profundas transformações diante das novas tecnologias de informações. Nesse sentido, surge o ciberativismo, uma forma de militância ativa e atuante através das redes sociais, que possibilita ampliar o espaço de discussão sobre determinado assunto. Assim posto, como instrumento facilitador de debates, as novas mídias dão visibilidade a ideologias e informações, e facilitam o engajamento do cidadão nas ações políticas. $\mathrm{O}$ artigo se utiliza de uma abordagem dedutiva e de observação direta junto ao site Greenpeace.org para compreender melhor a disseminação de campanhas públicas desse tradicional movimento ambientalista, e a contribuição na construção da cibercidadania. Diante da análise pode-se perceber que a organização dissemina os debates na esfera pública através da interatividade nas redes sociais.
\end{abstract}

PALAVRAS-CHAVE: Ativismo Digital; Cibercidadania; Novas Mídias; Meio Ambiente.

\section{INTRODUÇÃO}

O presente trabalho tem como finalidade analisar as configurações dos movimentos ambientalistas que fazem uso das novas tecnologias da comunicação e informação, especialmente a Internet, para promover suas ações neste ambiente com o auxílio dessas novas ferramentas.

Para a abordagem do tema, parte-se do estudo do ativismo digital e do exercício da cidadania proporcionado pelas novas mídias através da produção de informação crítica de temas relacionados com o meio ambiente e do movimento ambientalista nas redes sociais.

A Internet trouxe novas perspectivas e desafios para os movimentos ambientalistas, uma vez que possibilitou o exercício do poder democrático e cidadão desses, através da exposição de críticas, opiniões e sugestões postadas na rede. Essas novas relações modificaram a forma de relacionamento desses movimentos com o público em geral,

\footnotetext{
${ }^{1}$ Acadêmica do $7^{\mathbf{o}}$ semestre do Curso de Direito da Universidade Federal de Santa Maria (UFSM). Integrante do projeto de pesquisa "Ativismo digital e as novas mídias: desafios e oportunidades da cidadania global", desenvolvido no Curso de Direito da Universidade Federal de Santa Maria vinculado ao Núcleo de Direito Informacional da UFSM. E-mail para contato: noemi_fsantos@ hotmail.com

${ }^{2}$ Acadêmica do $7^{\circ}$ semestre do Curso de Direito da Universidade Federal de Santa Maria (UFSM). Integrante do Grupo de Pesquisa em Direito da Sociobiodiversidade. E-mail para contato: carinebelinazzo@yahoo.com.br

3 Acadêmica do $7^{\circ}$ semestre do Curso de Direito da Universidade Federal de Santa Maria (UFSM). Integrante do Grupo de Pesquisa em Direito da Sociobiodiversidade. E-mail para contato: jcm_dir@yahoo.om.br
} 


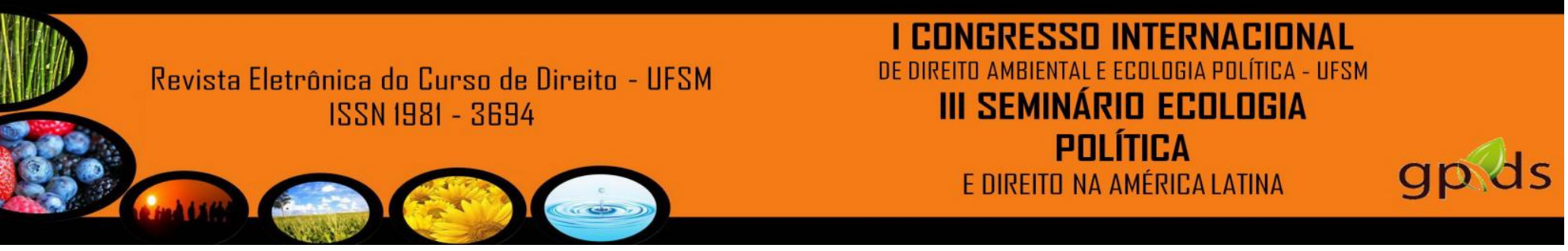

passando a exercer um novo ativismo na rede, o ciberativismo ambiental.

Para desenvolver o artigo empregou-se o método de abordagem dedutivo, identificando, primeiramente, os movimentos ambientalistas que atuam na Internet e suas ações nas redes sociais e posteriormente, analisando casos específicos que causaram reações por parte dos internautas, ambientalistas e ativistas, como as ações da organização nãogovernamental Greenpeace.

Partindo dessa metodologia, dividiu-se o trabalho em três tópicos: no primeiro, serão apresentadas as novas mídias e a sua relação com o ativismo digital. No segundo tópico será abordado o ativismo ambiental e as contribuições para a cibercidadania em rede. A seguir, serão abordadas ações ambientalistas do movimento da organização Greenpeace e o uso das redes sociais.

\section{As novas mídias e o ativismo digital}

As novas tecnologias de informação e comunicação (TICs), bem como o rádio, a televisão, a mídia impressa e mais recentemente a Internet revolucionaram os meios de comunicação e proporcionaram uma nova forma de relacionamento entre aquele que produz informação e aquele que a recebe.

A comunicação em rede e uma maior interação entre emissor e receptor somente foi possível com a criação e desenvolvimento da Internet em 1969, através da agência ARPANET (Advanced Research Projects Agency Network), a fim de facilitar a troca de informações entre as equipes do projeto e os laboratórios de pesquisa (MARQUES; MARTINS, 2006, p. 57).

Posteriormente surge a criação da World Wide Web por uma equipe coordenada por Tim Berners-Lee e Robert Cailliau no início da década de 1990, com o objetivo de compartilhar documentos científicos, tornando-se um meio de interação e comunicação entre pessoas em qualquer localização geográfica no mundo (MARQUES; MARTINS, 2006, p. 60).

As novas mídias, impulsionadas pela mundialização e desterritorialização da Internet, possibilitaram a utilização do termo sociedade da informação, que segundo Kelly Cristina Prudencio (2006, p. 17) a expressão significa:

Sociedade da informação é uma expressão recorrente nas análises recentes sobre a sociedade. Utilizada em diferentes contextos teóricos, designa geralmente um ambiente de relações sociais mediado por sistemas de informação cujo suporte tecnológico são as redes de computadores. A noção de conectividade que perpassa essas análises pressupõe uma sociedade global, na qual a informação está disponível numa rede eletrônica mundial de bibliotecas, arquivos e bancos de dados acessíveis, teoricamente, a qualquer pessoa em qualquer lugar a qualquer momento. 
A expressão sociedade da informação demonstra um novo paradigma da sociedade contemporânea, na qual a informação possui um valor essencial na transformação social, agregando novos serviços e novas oportunidades em um ambiente sem fronteiras e transnacional, onde a soberania deixa de ser um fator importante nas relações que envolvem essa nova sociedade.

Com isso, a Internet tem se constituído numa ferramenta multicanal que agrega vários tipos de mídia em um só ambiente, como por exemplo, textos, imagens, sons, vídeos, onde as interações ocorrem de maneira muito mais rápida e atingem um público cada vez maior de pessoas localizadas em várias partes do globo.

Nesse espaço, as informações circulam de forma livre e com diversas fontes despejando conteúdo na rede. Assim, a Internet contribui para um ambiente mais democrático e possível de interação, uma vez que os internautas têm a possibilidade de receber e armazenar uma quantidade de informações, mas, ao mesmo tempo, produzem conteúdo diversificado.

Os vários atores da rede organizam-se em um ambiente, como por exemplo, em um blog com o intuito de propagar suas ideias na forma de uma militância ativa e atuante na web. Trata-se de uma forma de ação política organizada que utiliza as tecnologias de informação e comunicação, nomeadamente, a Internet como veículo de propagação de ideologias ou informações, buscando a transformação da realidade.

Dessa forma surge o ativismo digital ou ciberativismo, como mecanismo de ação política no ambiente virtual, sendo definido por Maria Eugênia Rigitano (2003) como, "Entende-se por ciberativismo a utilização da internet por movimentos politicamente motivados pelo intuito de alcançar certas metas ou lutar contra injustiças que ocorrem na própria rede."

Internacionalmente, o ativismo digital ganhou força com os movimentos internacionais de direitos humanos, como a Anistia Internacional ${ }^{4}$ que atua enviando $e$ mails aos ativistas para que promovam ações recomendadas em nome da entidade, promovendo campanhas globais e recebendo denúncias de violações de direitos humanos.

4 Segundo a página eletrônica oficial do movimento "A Anistia Internacional é um movimento global integrado por pessoas, em sua maioria colaborando de forma voluntária, que trabalham para que os direitos humanos sejam respeitados em todo o mundo." (ANISTIA, 2012) 
No Brasil, o movimento ativista ganhou destaque com a realização do Fórum Social Mundial em janeiro de 2001, na cidade de Porto Alegre no Rio Grande do Sul. $\mathrm{Na}$ ocasião, as várias entidades civis e organizações não governamentais utilizaram-se da Internet para divulgar suas reivindicações e desenvolver espaços de debate e mobilização em favor dos direitos dos cidadãos (MORAES, 2001, p. 1).

A Internet proporciona a ampliação do espaço de ação dos movimentos sociais que estão organizados no ambiente tradicional, uma vez que passa a difundir informações e a veicular denúncias com o intuito de mobilizar uma quantidade razoável de pessoas em torno de uma causa específica ou de um tema.

Dessa forma, o ambiente virtual passa a ser visto como um canal de comunicação complementar onde os objetivos se unem em torno de um ideal, mobilizando internautas e criando espaço para discussões e protestos dentro e fora da rede mundial de computadores.

As novas mídias, em especial a Internet, não tendem a mobilizar o público em geral, mas comunidades localizadas de indivíduos, como bem observou Drica Guzzi (2010, p. 69) que afirma:

\footnotetext{
Nesse sentido, as mídias não tendem mais a se ligar a um público em geral, à massa, ao povo, mas a comunidades virtuais - temáticas ou locais - e à multidão expressa no comum, com vozes de enunciação locais que podem virtualmente se tornar vozes globais.
}

Com isso, grupos de interesses comuns passam a interagir conjuntamente, criando um ambiente de discussão que une pessoas de diferentes lugares e regiões, como por exemplo, os movimentos de proteção e conservação do meio ambiente que atuam na Internet, tema que será tratado no tópico seguinte com a abordagem da ciberdemocracia em rede através do ativismo ambiental.

\section{$2 \mathrm{O}$ ativismo ambiental na Internet e o exercício da cibercidadania em rede}

O desenvolvimento da sociedade da informação faz com que a Internet passe a ter um papel importante como ferramenta de debate e conscientização sobre assuntos que antes estavam esquecidos ou simplesmente não eram abordados pelas mídias tradicionais, como por exemplo, as mobilizações em torno do meio ambiente. 
O movimento ambientalista inicia sua afirmação como ativista político e social na década de 60 quando começam a pressionar organismos internacionais pela solução de problemas na esfera ambiental, principalmente na Europa, como uma reação alternativa à ordem capitalista dominante (McCORMIK, 1992).

No Brasil, o movimento ambientalista ganha contornos com a criação da Associação Gaúcha de Proteção ao Ambiente Natural (Agapan) fundada em Porto Alegre pelo ativista José Lutzemberger, em meados da década de 70, com objetivos amplos de preservação da natureza como forma de preservação da espécie humana (COSTA, 2012).

Com o desenvolvimento das novas mídias, os movimentos ambientalistas passaram a desenvolver ações neste ambiente através da colaboração política em rede. Segundo a visão de John Palfrey e Urs Gasser (2011, p. 288) a Internet não mudou a natureza da ação política, mas possibilitou os meios para se obter uma maior participação, pois para eles:

\begin{abstract}
A internet proporciona as ferramentas que capacitam as pessoas, jovens e velhas, a ter um maior nível de participação direta e pessoal no processo formal da política - se elas assim o quiserem. Nenhuma tecnologia nova vai fazer alguém ter experiência de conversão. O que a rede proporciona é uma plataforma cada vez mais útil e atrativa para aqueles que estão predispostos a serem ativos na vida cívica.
\end{abstract}

Com isso, vários movimentos de proteção e defesa do meio ambiente, bem como ambientalistas passaram a utilizar desta nova ferramenta como forma de divulgação de suas ações e para mobilizar um número cada vez maior de internautas para participarem da cidadania em rede.

O termo cidadania está associado à participação política do cidadão no espaço público através do exercício democrático do direito de voto e participação na cena política. Em analogia a vida virtual Pierre Lévy (1999b, p. 128-129) descreve como o comportamento do cibercidadão influencia as bases da cibercidadania através de "um conjunto de técnicas, de práticas, de atitudes, de modos de pensar e valores no ciberespaço".

O exercício da cibercidadania pode ser exercido no ambiente virtual através de movimentos sociais, como as ações ambientalistas que despontam com a expansão das 
inteligência coletiva, sendo esta conhecida como a inteligência que está em toda a parte e em tempo real é recriada por várias pessoas que concentram algum tipo de saber.

Com isso, o exercício cotidiano da cidadania pode ser exercido com o uso das novas tecnologias informacionais, proporcionando a tomada de decisões com a transposição da barreira de espaço e de tempo e através de uma maior transparência pela acessibilidade instantânea das informações.

O exercício da cidadania virtual não limita os espaços da cidadania tradicional, uma vez que possibilita o encontro de diferentes vozes e olhares sobre o mesmo tema, ao trazer para o debate público gerações diferentes, como por exemplo, as discussões nas redes sociais.

Desse modo, as discussões em torno da aprovação do novo Código Florestal brasileiro tomou conta das redes sociais com a criação do movimento 'Veta, Dilma!', a fim de sensibilizar a Presidenta da República a vetar o texto aprovado na Câmara dos Deputados.

A discussão contou com mais de duzentas organizações da sociedade civil, que encabeçaram uma campanha na rede social Twitter '\#florestafazadiferença' com a participação de celebridades e especialistas para explicar online pontos polêmicos do texto, como a anistia a desmatadores, tornando-se um dos assuntos mais abordados nessa rede social (MOVIMENTO, 2012).

Esse é um dos exemplos do ciberativismo ambiental, que demonstra como a rede pode ser organizada e estruturada pelos ativistas para divulgar suas ações. Dessa forma, a Internet tem sido uma aliada dos movimentos que se dedicam a defender causas ambientais de proteção do meio ambiente.

A seguir, será exposto informações sobre a organização não-governamental Greenpeace, que é um dos expoentes do movimento ambientalista mundial, bem como serão tecidas ações dos ambientalistas desse movimento nas redes sociais.

\section{0 ciberativismo do Greenpeace nas redes sociais}

O Greenpeace é uma organização não governamental, que enfoca os problemas ambientais globais através de campanhas e atos não-violentos. As atividades ao passo que enfocam a reflexão sobre a degradação do meio ambiente, também visam o 
comprometimento da sociedade para encontrar possíveis soluções que venham minimizar a destruição do planeta.

Em atuação desde 1972, o marco para o surgimento desse ativismo ambiental foi a união de um grupo de doze ativistas, que saíram em um barco de pesca da cidade em Vancouver, no Canadá em direção ao Alaska, com o desígnio de impedir a realização de testes nucleares dos Estados Unidos. Embora a embarcação não tenha nunca chegado ao destino proposto, tal ato foi amplamente publicado pela mídia mundial, e o lema de defesa ao meio ambiente e paz a qualquer preço acabava de ser lançado (CAMPOS, 2012, p. 53).

Diante disso, a idéia de que alguns indivíduos poderiam fazer a diferença para um planeta mais verde se espalhou pelo mundo, e hoje em 40 países são encontradas sedes do Greenpeace, que possuem sua independência econômica com a parceria de mais de três milhões de colaboradores (CAMPOS, 2012, p. 53).

No Brasil, o Greenpeace desenvolve debates e atos contra a degradação ambiental desde 1992, e compromete-se em levar a realidade e os desafios ambientais para a agenda política nacional e internacional. O boicote ao comércio de importação de resíduos tóxicos, a campanha enfatizando a necessidade de averiguação dos malefícios dos produtos transgênicos, em virtude do princípio da precaução, e a investigação sobre a exploração ilegal e predatória de madeira na Amazônia, são exemplos de bandeiras levantadas pela organização em nosso país (EM, 2010).

Assim, ao tomar conhecimento da possibilidade ou concretude de danos ao meio ambiente, sejam eles produzidos pelo poder público para desenvolvimento de projetos políticos ou econômicos, ou ainda emanem da esfera privada, a atuação da organização se pauta através de manifestações e protestos pacíficos que desafiam empresas e governos a mudarem de atitude, sendo conforme Pinto (2011, p.58):

O Greenpeace, em sua condição de movimento social mundialmente reconhecido, por meio de suas ações ativistas, busca chamar a atenção para os problemas ambientais causados pela ação do homem e das indústrias.

As manifestações dos ativistas ambientais do Greenpeace são amplamente divulgadas na imprensa brasileira, pois dotadas de irreverência e ousadia ganham repercussão midiática instantânea. No entanto, diante da evolução das tecnologias da 
informação, a ONG utiliza-se da inovação para criar diferentes formas de mobilização online, que viabilizem a divulgação de suas ações políticas e proporcionem a interação entre a sociedade e os temas em debate.

Desse modo, um instrumento hábil para difundir a comunicação no ciberespaço é a web página. O Greenpeace possui 51 endereços, um deles correspondendo à sede brasileira, através do acesso ao link www.greenpeace.org.br ou www.greenpeace.com.br, é utilizado como mecanismo informacional que almeja a visibilidade do público, como alude Pinto (2011, p. 77):

Verifica-se que os objetivos do Greenpeace são veiculados, na maioria das vezes, em seu site. Os jornais também informam os objetivos propostos pela organização, contudo, o site institucional, por sua própria função, desempenha melhor este papel. Na maioria das notícias veiculadas ali, há a exposição dos objetivos organizacionais para justificar as ações engendradas.

Em segundos, é possível conectar pessoas de todo mundo, sendo diversas as opções de interatividade, desde assinar petições online, encaminhar e-mails, comentar notícias, iniciar debates e fóruns sobre as campanhas, assistir vídeos que fomentam a causa ambiental no youtube, ou ainda seguir o grupo nas redes sociais, Orkut, Facebook, e Twitter. Além disso, é disponibilizado um boletim eletrônico para aqueles que realizarem o cadastro do e-mail, o que possibilita o posterior envio de mensagens informativas de campanhas e demais atividades da organização.

Neste ambiente virtual ocorre a apresentação da ONG, com o histórico das mobilizações que marcaram o seu surgimento em âmbito nacional e internacional, bem como são elencadas as áreas para as quais se dirige o ativismo ambiental: Amazônia, clima e energia, nuclear, oceanos e transgênicos. A partir desses temas serão produzidas as notícias dos relatórios, dos blogs e das campanhas de mobilização online.

Os internautas ao acessarem o site conhecerão as campanhas de ciberativismo, e as principais alegações e justificativas para o posicionamento político da organização. E através de frases entusiastas "Precisamos de sua ajuda" ou "Assine pelo desmatamento zero" são convidados a assinar petições ou cartas destinadas a órgãos públicos ou empresas privadas, as quais de alguma maneira estariam realizando ou deixando de realizar ações que a ONG tem por questionável. 
O desmatamento das florestas brasileiras há muitos anos vem sendo um dos principais temas do ativismo ambiental do Greenpeace Brasil, através da realização de pesquisas, da investigação ilegal de exploração da madeira e da constante luta para que a produção de gado e soja não avance ainda mais sobre esse bioma. Em meio à conflituosa votação do novo código florestal brasileiro, a ONG se utiliza do ciberespaço para a divulgação da campanha pública Liga das Florestas, que consiste no lançamento de um projeto de lei popular pelo desmatamento zero das matas, o texto dispõe (LIGA, 2012):

Artigo $1^{\circ}$ - Fica instituído o desmatamento zero no Brasil, com a proibição da supressão de florestas em todo o território nacional. A União, os Estados e o Distrito Federal não mais concederão autorizações de desmatamento das florestas nativas brasileiras.

Diante disso, o Projeto de Lei de Iniciativa Popular pelo desmatamento zero precisará receber assinaturas de $1 \%$ do eleitorado brasileiro, correspondendo a 1,4 milhões de assinaturas para ser apresentado na câmara dos deputados (LENZA, 2011, p. 499).

Com isso, o Greenpeace Brasil se utiliza das redes sociais para a divulgação da Liga das Florestas, incentivando os cidadãos a serem atuantes nessa coleta, como demonstra o apelo: "Juntos podemos levar para o Congresso uma lei popular pelo fim da destruição das florestas. Entre na Liga das Florestas. Assine, compartilhe, ajude a salvar a flora e a fauna nacionais e participe da construção de um futuro verde para o Brasil” (LIGA, 2012).

Assim, ao acessar o link www.greenpeace.org.br, o cidadão terá acesso ao manifesto Liga das Florestas, e através do preenchimento do espaço que contempla a solicitação de dados, como o nome completo, e-mail, telefone e data de nascimento assinará pelo desmatamento zero. Atualmente, a Liga das Florestas conta com 487.007 assinaturas online (LIGA, 2012), mas a meta é proporcionar um amplo debate sobre a temática, e mobilizar o máximo de internautas através da colaboração política em rede, suscitando o exercício da cibercidadania. 



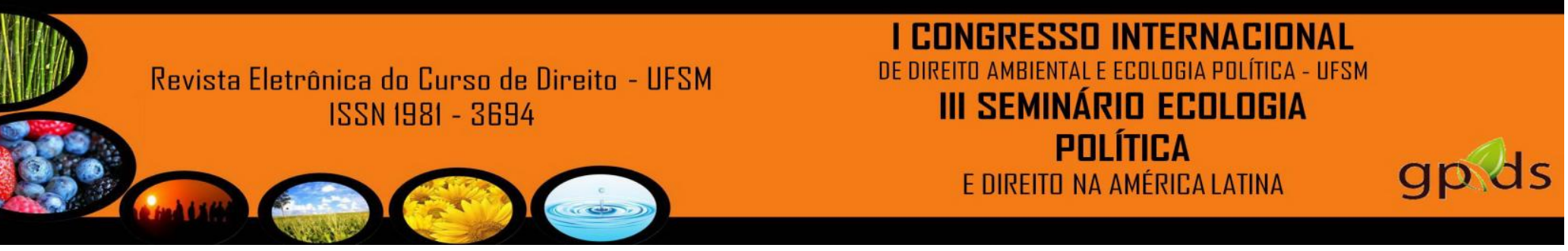

CAMPOS, Emilene de Oliveira. Ativismo na rede: informação, e espetáculo. Disponível em: <http://www.bdtd.uerj.br/tde_arquivos/19/TDE-2007-08-10T133641Z147/Publico/Diss_Emilene_pt1.pdf $>$ Acesso em: 01 set. 2012.

CASTELlS, Manuel. O Poder da Identidade: a era da informação - economia, sociedade e cultura, Vol 2. Tradução de Klauss Brandini Gerhar. 5 ed. São Paulo: Paz e Terra, 2006.

COSTA, Filipe Corrêa da. A evolução do movimento ambientalista brasileiro. Disponível em: <http://iesam.org.br/documentos/Movimento\%20Ambientalista.pdf> Acesso em: 02 set. 2012.

EM ação no Brasil. Publicado em 07 abr. 2010. Disponível em: $<$ http://www.greenpeace.org/brasil/pt/quemsomos/Greenpeace-no-Brasil/>. Acesso em 01 set. 2012.

GREENPEACE. Disponível em <http://www.greenpeace.org/brasil>. Acesso em: 02 set. 2012.

GUZZI, Drica. Web e participação: a democracia no século XXI. São Paulo: Senac São Paulo, 2010.

LENZA, Pedro. Direito constitucional esquematizado. 15. ed. São Paulo: Saraiva, 2011.

LÉVY, Pierre. A inteligência coletiva: por uma antropologia do ciberespaço. 2. ed.

Trad. Luiz Paulo Rouanet. São Paulo: Loyola, 1999a.

Cibercultura. São Paulo: Editora 34, 1999 b.

LIGA DAS FLORESTAS. Disponível em: http://www.ligadasflorestas.org.br/. Acesso em: 03 set. 2012

MANIFESTAÇÕES contra Belo Monte neste sábado em nove estados e no DF. Publicado em 13 dez. 2011. Disponível em: <http://www.xinguvivo.org.br/2011/12/13/manifestacoes-contra-belo-monte acontecem-em-sete-estados-esta-semana/> Acesso em: 02 set. 2012.

MARQUES, Garcia; MARTINS, Lourenço. Direito da Informática. 2. ed. Coimbra: Almedina, 2006.

McCORMIK, John. Rumo ao paraíso: a história do movimento ambientalista. Rio de Janeiro: Relume-Dumará, 1992.

MORAES, Dênis de. O ativismo digital. Rio de Janeiro: UFF, 2001. Disponível em: <http://www.bocc.uff.br/pag/moraes-denis-ativismo-digital.pdf> Acesso em 26 mar. 2012. 
